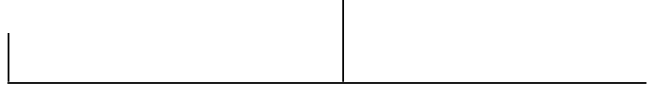

Rev. Latinoam. Psicopat. Fund., São Paulo, v. 12, n. 4, p. 698-713, dezembro 2009

\title{
Suicídio e sociedade: um estudo comparativo de Durkheim e Marx
}

Marta M. Assumpção Rodrigues

Este artigo trata do suicídio de uma perspectiva sociológica e comparativa. Salienta as diferenças e similitudes das obras $\mathrm{O}$ suicídio. Estudo sociológico, de Émile Durkheim, e Peuchet: sobre o suicídio, de Karl Marx, para mostrar que, apesar de cada um desses autores assumirem uma posição filosófica própria, o resultado de seus trabalhos é mais complementar do que antagônico: ambos buscam delimitar o campo da Sociologia como disciplina científica.

Palavras-chave: Suicídio, Sociologia, Durkheim, Marx 
Toda morte é um suicídio disfarçado

Sigmund Freud

Cuidado, não desperdice essa vida!

(Ditado zen-budista)

\section{Introdução}

Quando a obra $O$ suicídio. Estudo sociológico de Émile Durkheim (1858-1917) foi publicada pela primeira vez na França, em 1897, Karl Marx (1818-1883) já havia publicado na Alemanha, havia mais de 50 anos (1846), o ensaio intitulado Peuchet: sobre o suicídio ("Peuchet: vom Selbstmord", Gesellschaftsspiegel, ano II, n. VII, Elberfeldt, janeiro de 1846). Apesar de posteriormente publicada, foi a obra de Durkheim que se consagrou como o estudo sociológico clássico mais importante sobre o tema do suicídio; a de Marx praticamente caiu no esquecimento, ganhando sua primeira tradução para o inglês em 1975, numa coleção organizada em Moscou (Collected Works) e, para o francês, em 1983 (Gallimard). Com tradução de Rubens Enderle e Francisco Fontanella, o texto de Marx foi publicado em português em 2006 (Boitempo Editorial).

Este artigo pretende refazer o percurso trilhado por estes dois dos mais influentes sociólogos modernos, Émile Durkheim e Karl Marx, de uma perspectiva comparada. Nosso objetivo é demonstrar que estas duas obras que tratam, cada uma a seu modo, do tema do suicídio, constituem um marco importante na delimitação da Sociologia como disciplina rigorosamente objetiva. Nas duas primeiras partes, o artigo destaca as diferenças do pensamento sociológico de Durkheim e Marx com relação ao tema. Num terceiro momento, pretende-se demonstrar que, embora os caminhos trilhados por esses autores sejam diversos, pois cada um assume uma posição filosófica própria, ambos desembocam num resultado mais 
complementar do que antagônico. Afinal, motivos pessoais que levam os indivíduos a buscarem a morte de maneira deliberada podem funcionar como canais por onde forças coletivas também passam.

Se a obra de Durkheim enfatiza o suicídio como um fenômeno social, a de Marx desvela uma faceta desconhecida de um dos mais importantes pensadores da humanidade: suas idéias sobre as relações pessoais e sobre o mundo privado.

\section{Primeira Parte - Durkheim e o suicídio}

Se hoje o suicídio se constitui como objeto de estudo importante tanto no campo da psicologia e psicanálise quanto no campo sociológico, delimitar essa fronteira, no século XIX, não foi tarefa fácil. Para se consolidar como uma disciplina rigorosamente objetiva, a Sociologia deveria, antes de mais nada, utilizar uma metodologia científica própria que a distinguisse das outras ciências. Ao analisar o suicídio não como um fenômeno psicológico individual, mas como um fato social, Émile Durkheim (1977) visava, exatamente, fazer essa distinção, fundando, ao seu modo, o campo sociológico.

Assim, se, em vez de vermos neles [nos suicídios] apenas acontecimentos particulares, isolados uns dos outros e que necessitam cada um por si de um exame particular, considerarmos o conjunto dos suicídios cometidos numa sociedade dada durante uma unidade de tempo dada, constatamos que o total assim obtido não é uma simples soma de unidades independentes, um todo de coleção, mas que constitui em si um fato novo e sui generis, que possui a sua unidade e a sua individualidade, a sua natureza própria por conseguinte, e que, além disso, tal natureza é eminentemente social. (p. 14)

As expectativas de Durkheim em relação à Sociologia como disciplina científica eram tremendas. Por isso, a análise que ele nos oferece do suicídio não como um fato psicológico individual, ${ }^{1}$ mas como fato social, traduz tanto sua busca para delimitar a Sociologia como um campo científico autônomo, quanto a oposição que ele pretendia fazer com relação às orientações positivistas, que transformavam a investigação social numa dedução de fatos particulares a partir de leis supostamente universais - como preconizava Augusto Comte, por exemplo.

Sabe-se que Durkheim considerava os valores sociais como sendo determinados pela natureza particular das sociedades, e que a crítica desses valores po-

1. Para uma detalhada crítica sobre as fontes psiquiátricas utilizadas por Durkheim, ver Berrios e Mohanna (1990), Lloyd (1990) e Youssef (1990). 
deria abrir espaço para que a Sociologia formulasse uma ética que substituísse a moral. No entanto, seu estudo sobre o suicídio não se realiza a partir dessa ótica, isto é, a partir de uma crítica aos valores sociais estabelecidos. Pelo contrário. Para realizar a tarefa de dar tratamento sociológico ao fenômeno do suicídio, Durkheim foi pioneiro em lançar mão da estatística (Selvin, 1958) como uma maneira eficaz de conceituar de forma direta - e não através dos pensamentos e emoções individuais - o sistema das representações coletivas (entendido como consciência coletiva) da sociedade. Ao proceder assim, Durkheim traz a sociologia francesa à luz não como um fato isolado, mas como uma forma de "integrar-se no amplo esforço do pensamento contemporâneo de ressituar a questão da objetividade" (Giannotti, 1971, p. 96-97). Nesse sentido, a questão da objetividade não se refere exclusivamente a uma tomada de posição filosófica, mas principalmente à forma pela qual o conhecimento sociológico se produz. Talvez por isso, ao estudar o suicídio como fenômeno social, Durkheim (1977) diz que "partimos do exterior, que nos é imediatamente acessível, com o objetivo de atingir o interior" (p. 371, n. 12).

Embora considerado "coisa" (ou fato social), o fenômeno do suicídio não cai diretamente sob o olhar do sociólogo. É preciso, antes de mais nada, construir a especificidade do objeto sociológico. Por isso, logo na segunda página de O suicídio, Durkheim (1977) nos alerta para o fato de que a explicação sociológica consiste em comparação, e que o primeiro procedimento sobre o qual o investigador deve se debruçar é o de escolher os fatos que devem ser comparados. "Uma investigação científica só pode atingir o seu fim, se se debruçar sobre fatos comparáveis e tem tanto mais hipóteses de o conseguir quanto se certificar de ter reunido todos os fatos que podem ser utilmente comparados", diz o autor (p. 8).

Posto nesses termos, a primeira tarefa do investigador que quer apresentar uma explicação aos fatos estudados é a de estabelecer uma classe de equivalência que agrupe os fenômenos sociais a partir de uma estratégia de semelhança, descartando, assim, os fenômenos dessemelhantes. Esse procedimento implica uma tomada de posição que carrega enormes consequências para a própria compreensão do que venha a ser a coisa a ser explicada ou conhecida. Para ilustrar esse ponto, vejamos um exemplo.

Com o objetivo de apresentar uma explicação eminentemente social (e não psicológica ou biológica) para o suicídio, é necessário agrupar, dentre os diversos tipos de morte, aquelas cometidas pelas próprias vítimas, desde que estejam conscientes das consequências de seus atos. Nesse sentido, o autor nos oferece a seguinte definição de suicídio: "Chama-se de suicídio todo o caso de morte que resulta direta ou indiretamente de um ato positivo ou negativo praticado pela própria vítima, ato que a vítima sabia dever produzir este resultado" (p. 11). 
Essa definição precisa nos ajuda a excluir todas as mortes que não se referem ao conteúdo da palavra aqui definida. Ela se constitui como o primeiro passo para o estabelecimento do suicídio como fato (ou fenômeno) social. A partir daí, é possível estabelecer entre os diversos momentos históricos de uma dada sociedade, ou mesmo de sociedades diferentes, os termos de comparação que possibilitem estabelecer uma classe de semelhança. Assim, ao estabelecer o critério que rege a comparação, Durkheim esclarece sua posição: se "cada suicídio constitui um acontecimento particular e insubstituível; a comparação feita pelo cientista não destrói sua singularidade, apenas o integra numa classe de semelhança, na medida em que vê em todas essas mortes traços comuns" (Giannotti, 1971, p. 52).

A partir daí, a explicação sociológica do fenômeno do suicídio como fato social depende da elaboração de uma taxa social de suicídios, que se constitui por uma tendência, presente em todas as sociedades, de uma "aptidão definida para o suicídio" (Durkheim, 1977, p. 16). Trata-se, agora, não de examinar no que consiste essa tendência - "se é um estado sui generis da alma coletiva, com sua realidade própria, ou se representa apenas uma soma de estados individuais" (p. 20-21) -, mas sim de assumir um critério que quantifique essa aptidão definida para o suicídio por um longo período de tempo. Afinal, o enfoque do suicídio como fato social mostra que "Cada sociedade está predisposta a fornecer um determinado contingente de mortos voluntários" (p. 21). Esse critério é o que Durkheim denomina de taxa social dos suicídios, que é medida a partir do seguinte procedimento:

Mede-se a intensidade relativa desta aptidão tomando a relação entre o número global de mortos voluntários e a população global (todas as idades e ambos os sexos). Designaremos este dado numérico por taxa de mortalidade-suicídio própria à sociedade considerada. Esta taxa é geralmente considerada relativamente a um milhão ou a cem mil habitantes. (p. 16)

Em suma, se o inventário das condições que determinam os suicídios particulares é preocupação dos psicólogos, o que o sociólogo

(...) procura são as causas através das quais é possível agir, não sobre os indivíduos isolados, mas sobre o grupo. Por conseguinte, entre os fatores dos suicídios, os únicos que lhe dizem respeito (ao sociólogo) são os que se fazem sentir no conjunto da sociedade. A taxa dos suicídios é o produto destes fatores. É por isso que nos vamos debruçar sobre eles. (p. 21)

Isso significa dizer que já que toda sociedade tem uma "aptidão definida para o suicídio" que parece invariável e constante durante longos períodos de tempo, é tarefa do sociólogo responder à questão: por que existe em toda e qualquer 
sociedade uma predisposição para oferecer um determinado contingente (constante e invariável por um razoável período de tempo) de mortos voluntários?

Para responder a essa pergunta, Durkheim empreende seu trabalho em três etapas. Na primeira parte o autor analisa as causas extrassociais de uma grande generalidade para concluir que sua influência é nula ou muito restrita. Na segunda parte, Durkheim (1977) examina as causas propriamente sociais, seus efeitos e suas relações com os estados individuais que acompanham as diversas espécies de suicídio para concluir que "A evolução do suicídio é assim composta por ondas de movimento, distintas e sucessivas, que se verificam por arranques, se desenvolvem durante um tempo, para depois estacionar, para em seguida recomeçar" (p. 16). Por fim, na última parte do trabalho, o autor nos esclarece no que consiste essa tendência coletiva para o suicídio, para concluir que seu fator explicativo é a maneira como o tempo age no indivíduo sobre a tendência para o suicídio.

O que explica, julgamos nós, esta temporização, é a maneira como o tempo age sobre a tendência para o suicídio. É um fator auxiliar mas importante desta. Com efeito, é do conhecimento geral que esta progride ininterruptamente desde a juventude até a maturidade, e que é dez vezes mais elevada no fim da vida do que no princípio. Portanto, a força coletiva que leva o homem a matar-se vai penetrando nele lentamente. Nas mesmas condições, é à medida que a idade avança que o homem se torna mais acessível, sem dúvida porque necessita de experiências repetidas para sentir o vazio de uma existência egoísta ou a pobreza das ambições sem limites. Eis a razão por que os suicídios só cumprem o seu destino por camadas sucessivas de gerações. (p. 382-383)

Considerando a produção científica anterior a Durkheim verificamos que ele não foi o primeiro a reconhecer que taxas de suicídio podem ser explicadas sociologicamente; mas nenhum autor antes dele havia pensado numa teoria que pudesse interpretar, de uma perspectiva sociológica, as principais correlações empíricas que já haviam sido estabelecidas (Giddens, 1965).

Pelo que foi dito até aqui, seria de se esperar que a obra de Durkheim, tão conhecida, tão abrangente e tão consagrada, tivesse imprimido uma metodologia definitiva na constituição do suicídio como objeto de estudo da Sociologia, deixando pouco espaço para reflexões de outra ordem de fatos. Entretanto, como se pretende mostrar na próxima sessão, do estudo que Marx nos apresenta sobre o tema do suicídio vem à tona uma outra possibilidade de investigação sociológica. Se Durkheim partiu do exterior para atingir o interior, Marx, por sua vez, parte da análise da vida privada para realizar uma crítica social contundente. 


\section{Segunda Parte - Marx e o suicídio}

Se $O$ suicídio de Émile Durkheim é uma obra rigorosamente científica, Sobre o suicídio de Karl Marx é, acima de tudo, uma obra curiosa. Primeiro porque ela não faz uso da estatística para delimitar a fronteira do campo sociológico. Pelo contrário, ao analisar o tema do suicídio a partir da metodologia do estudo de caso, Marx acaba por aproximar a Sociologia das outras ciências humanas. E, ao fazê-lo, este autor nos apresenta não o que esta Ciência Social tem de específico, mas, sim, o que ela tem de comum com as outras ciências do homem. Segundo, trata-se de uma obra curiosa também porque ela é composta de excertos traduzidos para o alemão das memórias (Mémoires tirés des archives de la police de Paris, depuis Louis XIV jusqu'à nous jours, 1838), de Jacques Peuchet (1758-1830) - que não foi nem filósofo, nem historiador, nem mesmo socialista, mas, apenas, um diretor dos Arquivos da Polícia francesa durante a Restauração. Nela, Marx nos apresenta comentários informais sobre temas que Peuchet relatou no capítulo "Du suicide et des ses causes" como a vida, a morte, a família, o aborto, a escravidão, o patriarcado, o feminismo. É sabido que Marx costumava preencher cadernos inteiros com excertos desse tipo (Gonzalez, 1984). Mas este foi o único caderno de notas que ele não só publicou, mas publicou com a sua própria assinatura.

Publicado na revista alemã intitulada Gesellschaftsspiegel (Espelho da sociedade), em 1846, este ensaio foi preparado durante o período de exílio que Marx viveu com sua família na Bélgica (1845-1848). Em Bruxelas, Marx decidiu renunciar à cidadania alemã e desenvolveu uma intensa atividade intelectual. Preparou com seu amigo Friedrich Engels os manuscritos de A ideologia alemã e do Manifesto do Partido Comunista, e escreveu A miséria da filosofia e suas Teses contra Feuerbach, que foram encontradas por Engels junto aos manuscritos de A ideologia alemã depois de sua morte (Gonzalez, 1984).

Durante sua estada na Bélgica, Marx demonstrou bastante entusiasmo com a literatura em geral e, em especial, com as obras de Dante e Balzac. Certa vez, ele declarou ter aprendido muito mais sobre a sociedade burguesa nos romances de Balzac do que em centenas de tratados econômicos (Löwy, 2006, p. 15). (Aliás, fora exatamente num outro capítulo escrito por Peuchet que Alexandre Dumas se inspirou para escrever $O$ conde de Monte Cristo, tomando como base a história da vida real de François Picaud).

O valor do texto de Peuchet, como o próprio Marx nos explica na introdução de seu ensaio, é que, ao estudar casos de suicídio, Peuchet nos apresenta "a crítica francesa da sociedade" com respeito às condições da vida moderna. Trata-se, vale enfatizar, da crítica francesa à sociedade moderna e não de uma crí- 
tica da sociedade francesa. Por isso, mais de cento e cinquenta anos depois de sua primeira publicação, Sobre o suicídio é uma obra que impressiona pela atualidade.

Ao escrever sobre o tema do suicídio, Marx imprime sua marca sem deixar de salientar uma profunda afinidade temática com seu "coautor". Essa afinidade se revela no tom da crítica social (e institucional) que o texto nos apresenta sobre a vida privada. O leitor que se depara com a descrição que Peuchet/Marx fazem da história de vida desses suicidas fica tentado a refazer o argumento de La Boetie às avessas, em que a vida pode ser pensada não pela ótica da servidão voluntária, mas pela da servidão involuntária. Há momentos em que o ensaio chega a soar como uma espécie de arqueologia da alma humana; noutros, soa como um tratado antropológico da sociedade partida. De qualquer forma, a impressão mais marcante que esse livro provoca no leitor é a de que Peuchet ajudou Marx a assumir e explorar temas que ele, só, talvez não enfrentaria.

Há quem diga que o fato de Marx ter escolhido Jacques Peuchet tenha sido uma forma de protesto contra o "verdadeiro socialismo" alemão (Bourrinet, 1992, p. 9-27) - o que parece muito pouco provável. Outros, como Kevin Anderson e Eric Plaut (1999), consideraram que a escolha de Marx pelo texto de Peuchet se deveu a uma "inconsciente" fascinação que ele teria alimentado sobre o suicídio - argumento que parece, também, sem fundamento ou, pelo menos, de comprovação impossível. O fato é que Marx se impressionou com o texto de Peuchet, porque ele nos apresenta uma sociedade doente que clama por uma transformação radical.

Citando Rousseau, Peuchet e Marx descrevem a sociedade moderna como um deserto; um deserto habitado por bestas selvagens. Sem citar Hobbes, descrevem vidas que se deslindam no reino da hostilidade, cuja regra é a de todos contra todos. Nesse ambiente, restam aos indivíduos apenas duas alternativas: ser vítima ou carrasco (Löwy, 2006, p. 16). Este é o contexto social que explica o suicídio e o desespero dessas vítimas.

A obra Sobre o suicídio não tem nada a ver com política e economia. E, ao mesmo tempo, tem tudo a ver com economia e política, na medida em que ela enfatiza males de toda ordem como causa dos suicídios: a miséria, o desemprego, os salários aviltantes, a prostituição, a injustiça social.

O número anual dos suicídios, aquele que entre nós é tido como uma média normal e periódica, deve ser considerado um sintoma da organização deficiente [um vício constitutivo, diz Peuchet] de nossa sociedade; pois, na época da paralisação e das crises da indústria, em temporadas de encarecimento dos meios de vida e de invernos rigorosos, esse sintoma é sempre mais evidente e assume um caráter epidêmico. A prostituição e o latrocínio aumentam, então, na

Rev. Latinoam. Psicopat. Fund., São Paulo, v. 12, n. 4, p. 698-713, dezembro 2009 
mesma proporção. Embora a miséria seja a maior causa do suicídio, encontramo-lo em todas as classes, tanto entre os ricos ociosos como entre os artistas e os políticos. A diversidade das suas causas parece escapar à censura uniforme e insensível dos moralistas.

As doenças debilitantes, contra as quais a atual ciência é inócua e insuficiente, as falsas amizades, os amores traídos, os acessos de desânimo, os sofrimentos familiares, as rivalidades sufocantes, o desgosto de uma vida monótona, um entusiasmo frustrado e reprimido são muito seguramente razões de suicídio para pessoas de um meio social mais abastado, e até o próprio amor à vida, essa força enérgica que impulsiona a personalidade, é frequentemente capaz de levar uma pessoa a livrar-se de uma existência detestável. (Marx, 2006, p. 24-25)

Pelo que foi dito acima, podemos pensar que a crítica social que esta obra nos oferece não se limita à exploração econômica. Ela se refere, fundamentalmente, ao caráter (ou à falta de caráter) ético e social da sociedade moderna. Os casos de que este ensaio se ocupa desvelam o drama cotidiano da vida de todos os indivíduos, independentemente da classe social a que pertencem. ${ }^{2}$ Afinal, como Durkheim, Marx também acreditava que os valores sociais são determinados pela natureza particular das sociedades e, como ele mesmo afirma no texto, uma sociedade de natureza desumana fere a todos, das mais diversas origens sociais.

Contudo, um olhar apurado sobre os casos estudados neste ensaio nos mostra que os temas discutidos aqui - em especial, o patriarcado, a natureza opressiva da família burguesa e a escravidão - demonstram que a desumanidade da sociedade moderna fere ainda mais as mulheres. Afinal, dentre os quatro suicídios analisados aqui, três são cometidos por mulheres.

Vejamos os casos:

Caso 1 - Julho de 1816, uma jovem passa a noite anterior ao seu casamento fora de casa com seu noivo e é levada ao suicídio pelos pais, que a receberam pela manhã furiosamente. Envergonhada, a jovem correu para o rio Sena e jogou-se na água.

As pessoas mais covardes - diz Marx (2006) -, (...) tornam-se intolerantes assim que podem lançar mão de sua autoridade absoluta (...) o mau uso dessa autoridade é igualmente uma compreensão grosseira para o servilismo e a subordinação aos quais essas pessoas estão submetidas, de bom ou de mau grado, na sociedade burguesa. (p. 32)

2. Talvez por esse motivo, os casos apresentados aqui não incluem socialistas. Mas isso não tem a menor importância, pois, como afirma o próprio Marx na introdução ao artigo, não é preciso ser socialista para criticar a ordem estabelecida. Nem para vivenciar as mazelas humanas. 
Caso 2 - 1816 - Uma linda jovem da Martinica é afastada do convívio social pelo marido que foi tomado pela loucura e pelo ciúme. Levada ao desespero, comete suicídio.

Certamente (...) esse suicídio foi um assassinato, praticado pelo esposo; mas foi também o resultado de uma extraordinária vertigem de ciúme. O ciumento necessita de um escravo; o ciumento pode amar, mas o amor é para ele apenas um sentimento extravagante; o ciumento é antes de tudo um proprietário privado. (p. 42)

Caso 3 - Uma mulher grávida, que não consegue realizar um aborto, põe fim a sua vida depois de "deslizar para dentro de um regato na propriedade de seus tutores, em Villemomble” (p. 48).

Com este caso, "Vê-se que, na ausência de algo melhor, o suicídio é o último recurso contra os males da vida privada" (p. 48).

Caso 4 - Um homem é afastado do trabalho, cai em profundo desânimo e se mata.

O suicídio elimina a pior parte da dificuldade, o cadafalso ocupa-se com o resto. Somente com uma reforma no nosso sistema geral de agricultura e indústria pode-se esperar por fontes de recursos e por uma verdadeira riqueza. (p. 50)

Pelo que demonstram os casos estudados, a crítica que Marx realizou neste ensaio, com a ajuda de Peuchet, não se dirige exclusivamente à sociedade machista, à opressão familiar nem ao patriarcado. Na realidade, ele fez uso desses exemplos para atribuir um caráter mais amplo a sua crítica social. Tanto que, na conclusão final do ensaio, Marx resgata, por exemplo, as instituições sociais como uma forma eficaz de suavizar os males daqueles que almejam ampliar seus direitos de cidadania para todos. Afinal, sociedades não divididas só podem sobreviver no livre exercício de relações francas entre iguais.

Nos pergaminhos, podemos facilmente proclamar constituições, o direito de todo cidadão à educação, ao trabalho e, sobretudo, a um mínimo de meios de subsistência. Mas, com isso, não se fez tudo; ao se escreverem esses desejos generosos sobre o papel, persiste a verdadeira tarefa de fazer frutificar essas ideias liberais por meio de instituições materiais e inteligentes, por meio de instituições sociais. (p. 50)

Por tudo o que foi dito até aqui, esta publicação traz não só novos ares à Sociologia, mas principalmente nos oferece a oportunidade de percebermos uma espécie de reviravolta na forma pela qual concebemos a interpretação do jovem Marx sobre os desafios e limites que a vida enfrenta ao ser vivida na sociedade moderna. 


\section{Terceira Parte - Considerações finais}

Este artigo pretendeu percorrer o caminho trilhado por dois sociólogos clássicos, Émile Durkheim e Karl Marx, ao examinarem a questão do suicídio. A ideia que norteou este trabalho teve o propósito de chamar a atenção para o fato de que aprimorar nosso conhecimento sobre a sociedade em que vivemos e sobre quem somos enquanto indivíduos e agentes sociais pressupõe lançar mão de múltiplos olhares que focalizem a relação que travamos entre interior/exterior.

Ao focalizar o suicídio como fato social, Durkheim (1977) buscou descobrir "as causas através das quais é possível agir, não sobre os indivíduos isolados, mas sobre o grupo" (p. 21). Assim, a questão que esse autor enfrentou nesse seu trabalho foi: quais as causas sociais do suicídio?

Para responder a essa pergunta, lhe interessou examinar, entre os diversos fatores que levam ao suicídio, apenas aqueles "que se fazem sentir no conjunto da sociedade" (p. 21); por isso, nosso autor dirige seu olhar também para a história. Afinal, "Cada sociedade tem, em cada momento de sua história, uma aptidão definida para o suicídio" (p. 16).

Nesse sentido, se é verdade que a "sociedade está [sempre] disposta a fornecer um determinado contingente de mortos voluntários", as oscilações que a estatística registra "exprimem a tendência para o suicídio de que cada sociedade está coletivamente afetada" (p. 20). No caso da França, por exemplo, a tendência de suicídios, entre 1856-1860, mostrou que mais mulheres puseram fim à vida por motivos de "perturbações mentais/loucura religiosa" do que homens, enquanto os homens cometeram mais suicídios do que as mulheres por motivo de "miséria/reveses da sorte" (p. 153, Q. XVII). Esses dados nos apresentam algumas pistas importantes sobre o perfil da sociedade francesa do século XIX.

Durkheim não focaliza, em seu trabalho, as dificuldades que os psicólogos enfrentam para detectar as razões/condições que levam o indivíduo isolado a pôr fim em sua vida, pois mesmo que elas fossem descobertas, este fato não necessariamente resultaria numa indicação de "que a sociedade IN GLOBO tenha uma propensão mais ou menos intensa para o suicídio" (p. 21). Mas, ao refletir sobre as dificuldades que o sociólogo encontra ao analisar esse tema, o autor enfatiza o risco que corremos quando nos utilizamos das "estatísticas dos motivos de suicídio" ofertadas por "funcionários, muitas vezes subalternos, encarregados deste tipo de informação"; afinal, diz ele, "Sabe-se, infelizmente, que as considerações oficiais são muitas vezes duvidosas" (p. 152).

De outra perspectiva, Karl Marx, que neste ensaio tomou a decisão deliberada de lançar mão de dados "oficiais" exatamente porque os considerava (no caso de Peuchet) fidedignos, atribuiu a maior dificuldade que o sociólogo enfrenta para 
realizar seu trabalho à sua capacidade de compreender e interpretar o drama da sociedade partida. Nesse sentido, ao estudar o suicídio a partir de um capítulo das memórias do ex-arquivista policial francês, Marx pareceu querer demonstrar que, na verdade, seu interesse sobre esse tema recaía mais sobre a construção de uma crítica radical da sociedade moderna e menos sobre a questão do suicídio propriamente dita.

Seu ensaio partiu da premissa de que sociedades diferentes geram diferentes produtos. "Os tártaros", por exemplo, "não se suicidam", diria Marx (2006, p. 25). Por isso, é a natureza de nossa sociedade que gera muitos suicídios. Segundo nosso autor, o reconhecimento desse fato é fundamental para "trabalharmos na reforma de nossa sociedade e permitir-lhe que se eleve a um patamar mais alto" (p. 25).

$\mathrm{Na}$ tentativa de compreender melhor a natureza de nossa sociedade, Marx dirige seu olhar para as angústias da existência humana e, ao fazê-lo, nos apresenta suas reflexões sobre temas que ainda permanecem, nos dias de hoje, atuais - como o direito ao aborto, a questão da mulher e a opressão familiar, entre outros. Assim, ao contrário de Durkheim, que partiu do exterior para atingir o interior, Marx realizou o caminho inverso: sua crítica social partiu do interior, das relações da vida privada, pois "a crítica da vida privada surge como o necessário resultado de suas experiências políticas" (p. 22).

$*$

Hoje o suicídio é encarado como um problema de saúde pública. Para o mundo, esta prática representa $1,5 \%$ do custo total das doenças sobre a sociedade. ${ }^{3}$ Por esse motivo, a Organização Mundial de Saúde (OMS) lançou, em 1999, o SUPRE (Suicide Prevention Program), um programa internacional que é composto por uma série de manuais destinados a profissionais de diversas áreas (médicos, jornalistas, professores) para orientá-los na prevenção do suicídio.

Dados recentes da OMS (www.who.int) mostram que a tendência em todos os países (exceto a China) é que homens cometem mais suicídios do que as mulheres, e que esta proporção tende a aumentar na medida em que eles envelhecem. Esse achado, que contradiz a impressão de Marx de que as mulheres tendem a se matar mais do que os homens, por sua vez, corrobora com a hipótese durkheiminiana de que a maneira como o tempo age sobre o indivíduo é um fator explicativo preponderante sobre a tendência do suicídio como fato social.

De outra perspectiva, dados da OMS mostram também que, depois da queda do Muro de Berlim, a taxa de suicídios aumentou significativamente em alguns países da Europa do Leste. A tabela, a seguir, apresenta esses números:

3. Folha de S. Paulo, 9/9/2004, "Suicídio mata mais do que a violência urbana e guerras". 
Tabela 1

Taxa de suicídios (por 100.000), segundo gênero, 1985 e 1995.

\begin{tabular}{|c|c|c|c|}
\hline & & 1985 & 1995 \\
\hline Lituânia - Total & & 34,1 & 45,6 \\
\hline & Homens & 58,0 & 79,1 \\
\hline & Mulheres & 12,9 & 15,6 \\
\hline Rússia - Total & & 31,2 & 41,5 \\
\hline & Homens & 52,9 & 72,9 \\
\hline & Mulheres & 12,3 & 13,7 \\
\hline Estônia - Total & & 22,3 & 40,1 \\
\hline & Homens & 32,5 & 67,6 \\
\hline & Mulheres & 12,8 & 16,0 \\
\hline Brasil - Total & & 3,2 & 4,1 \\
\hline & Homens & 4,7 & 6,5 \\
\hline & Mulheres & 1,6 & 1,7 \\
\hline
\end{tabular}

Fonte: OMS.

Tomando em consideração o ano de 1987 (queda do Muro de Berlim), podemos considerar que o aumento dos suicídios nos três países da Europa do Leste, entre 1985 e 1995, registrado na tabela acima, corrobora com a hipótese que "em épocas de crise, o sintoma do suicídio é sempre mais evidente e assume caráter epidêmico" (Marx, 2006, p. 24), tomando a forma de "ondas" que "se verificam por arranques" e "se desenvolvem ao longo do tempo" (Durkheim, 1977, p. 14). Em outras palavras, apesar de o número de suicídios ser "pouco mais ou menos variável", essas variações "são sempre contemporâneas de alguma crise que venha afetar o estado social” (p. 14). Nesses contextos, acrescenta Marx (2006), o crime e a violência aumentam na mesma proporção (p. 24). 
Enquanto alguns países da Europa do Leste registram taxas alarmantes de suicídio, a América Latina é a região que apresenta a menor incidência de suicídios. Aqui, o problema social de maior preponderância se focaliza no fenômeno da violência urbana.

Para ilustrar esse ponto, chamamos a atenção para um estudo de Adorno (2002) que revela que, no Brasil, ao longo da década de 1980, enquanto o número total de óbitos cresceu 20\%, o de óbitos motivados por causas violentas cresceu $60 \%$. Segundo o autor, dados internacionais para 1995 mostram que, enquanto nos Estados Unidos a taxa de homicídios por 100.000/hab foi da ordem de 8,2 e na Grã-Bretanha, de 2,4, no Brasil alcançou a cifra de 23,83 no mesmo ano. Em 1997, os dados indicavam 65,79 para as capitais do Rio de Janeiro e 56,69 para São Paulo. Bairros de maior vulnerabilidade socioeconômica (como o Jardim Ângela, em São Paulo) registram dados assustadores: 111,52/100.000 hab., em 1995. As taxas de homicídios no grupo etário entre 15-19 anos do sexo masculino, na cidade de São Paulo, saltaram de 9,6 para 186,7/100.000 hab. de 1960-1995. A maior taxa de homicídios é cometida com emprego de arma de fogo, que representava 50\%, em 1975, ultrapassando 80\%, em 1991 (www.nev.prp.usp.br).

Se, por um lado, esses dados desvelam pistas sobre uma sociedade que, como diria Marx, clama por transformações radicais, por outro não podemos desconsiderar a ideia, de Freud, de que a morte nos chega por vontade própria.

Nesse embate, resta-nos apenas, e a partir do aprendizado que adquirimos com nossos autores, formular políticas que, levando em consideração quem somos, ajudem-nos a não desperdiçar mais vidas.

\section{Referências}

Adorno, S. Exclusão socioeconômica e violência urbana. Sociologias, Porto Alegre, ano 4, n. 8, p. 84-135, jul.-dez. 2002.

Anderson, K.; Plaut, E. Marx On Suicide. Evanston: Northwest University Press, 1999.

Berrios, G.E.; Mohanna, M. Durkheim and French psychiatric views on suicide during the 19th century, British Journal of Psychiatry, n. 156, p. 1-9, 1990.

Bourrinet, P. Présentation. In: Marx, K.; Peuchet, J. À propôs du suicide. Castelnaule-Lez: Climats, 1992.

Durkheim, É. O suicídio. Estudo sociológico. Trad. de Luz Cary, Margarida Garrido e J.Vasconcelos Esteves. 2. ed. Lisboa: Editorial Presença, 1977.

FREUD, S. Entrevista a George Sylvester Viereck. Glimpses of the Great. New York/ London/Berlim, 1930. 
Giannotti, J. A. A sociedade como técnica da razão. Um ensaio sobre Durkheim. Estudos Cebrap, São Paulo, n. 1, p. 48-98, 1971.

GidDEns, A. The suicide problem in French sociology. British Journal of Sociology, v. 16, n. 1, p. 3-18, 1965.

GonZalez, H. Marx. O apanhador de sinais. São Paulo: Brasiliense, 1984.

La Boetie, E. Discurso da servidão voluntária. Trad. de Laymert Garcia dos Santos. São Paulo: Brasiliense, 1982.

LLOYD, K. Le suicide. British Journal of Psychiatry, n. 156, p. 593-594, 1990.

LÖwy, M. Um Marx insólito. In: MARX, K. Sobre o suicídio. São Paulo: Boitempo, 2006.

MARX, K. Entrevista a R. Landor. The World, Londres, 18 de julho de 1871. . Os Pensadores. São Paulo: Abril Cultural, 1978. . Sobre o suicídio. São Paulo: Boitempo, 2006.

NunEs, E.D. O suicídio reavaliando um clássico da literatura sociológica do século XIX. Cadernos de Saúde Pública, Rio de Janeiro, v. 14, n. 1, p. 7-34, jan-mar. 1998.

Peuchet, J. Du suicide et dês sés causes. Mémoires tirés des archives de la police de Paris, depuis Louis XIV jusqu'à nous jours, 6 tomos (Paris: A. Levavasseur et Cia, 1838). Elibron Classics Replica edition (a trademark of Adamant Media Corporation) is an unabridged facsimile of this edition, 2006.

Selvin, H.C. Durkheim's suicide and problems of empirical research. American Journal of Sociology, n. 63, p. 607-619, 1958.

Youssef, H. Durkheim's views on suicide. British Journal of Psychiatry, n. 156, p. 750, 1990.

\section{Resumos}

(Suicidio y sociedad: un estudio comparativo de Durkheim y Marx)

El presente artículo trata del suicidio desde una perspectiva sociológica y comparativa. Subraya las diferencias y similitudes de las obras El suicidio, estudio sociológico, de Émile Durkheim, e Peuchet: sobre el suicidio, de Karl Marx, para mostrar que, a pesar de que cada uno de ellos asumieran una posición filosófica propia, el resultado de sus trabajos es más complementario de lo que antagónico: ambos buscan delimitar el campo de la Sociología como disciplina científica.

Palabras clave: Suicidio, sociología, Durkheim, Marx 
(Suicide et société. Une étude comparative de Durkheim et Marx)

Cet article traite du suicide d'un point de vue sociologique et comparatif. Il met en relief les différences et les similitudes entre le oeuvres Le suicide, une étude sociologique, d'Émile Durkheim et Peuchet: a propos du suicide, de Karl Marx pour montrer que, bien que chaque auteur défend une position philosophique propre, le résultat de leurs travaux sont plutôt complémentaires qu'antagonistes: ils cherchent tous deux à définir le champ de la sociologie comme discipline scientifique.

Mots clés: Suicide, sociologie, Durkheim, Marx

(Suicide and society - A comparative study of Durkheim and Marx)

This article discusses suicide from a sociological and comparative perspective. It emphasizes differences and similarities of two books, namely, Suicide. A Study in Sociology, by Emile Durkheim and Peuchet: On Suicide, by Karl Marx. The text shows that, although the above authors start off from different philosophical premises, their works are complementary, as they both aim to demarcate the sociological field.

Key words: Suicide, sociology, Durkheim, Marx

Citação/Citation: Rodrigues, M.M.A. Suicídio e sociedade. Um estudo comparativo de Durkheim e Marx. Revista Latinoamericana de Psicopatologia Fundamental, São Paulo, v. 12, n. 4, p. 698-713, dez. 2009.

Editor do artigo/Editor: Prof. Dr. Manoel Tosta Berlinck

Recebido/Received: 27.07.2008 / 7.27.2008 Aceito/Accepted: 6.10.2008 / 10.6.2008

Copyright: $\odot 2009$ Associação Universitária de Pesquisa em Psicopatologia Fundamental/ University Association for Research in Fundamental Psychopathology. Este é um artigo de livre acesso, que permite uso irrestrito, distribuição e reprodução em qualquer meio, desde que $o$ autor $\mathrm{e}$ a fonte sejam citados/This is an open-access article, which permits unrestricted use, distribution, and reproduction in any medium, provided the original author and source are credited.

Financiamento/Funding: A autora declara não ter sido financiada ou apoiada/The author has no support or funding to report.

Conflito de interesses: A autora declara que não há conflito de interesses/The author declares that has no conflict of interest.

\section{Marta Maria Assumpção Rodrigues}

Ph.D em Ciência Política pela Universidade de Notre Dame (EUA); professora de Gestão de Políticas Públicas na Escola de Artes, Ciências e Humanidades da Universidade de São Paulo - EACH/USP (São Paulo, SP, Brasil); pesquisadora do Núcleo de Pesquisa de Políticas Públicas da Universidade de São Paulo - NUPPs/USP.

e-mail: mmar@usp.br

Rev. Latinoam. Psicopat. Fund., São Paulo, v. 12, n. 4, p. 698-713, dezembro 2009 